\title{
THE EFFECT OF A SIDE-TO-SIDE PORTACAVAL SHUNT ON HEPATIC HEMODYNAMICS IN CIRRHOSIS *
}

\author{
By TELFER B. REYNOLDS, WILLIAM P. MIKKELSEN, ALLAN G. REDEKER AND \\ HARRY S. YAMAHIRO $\dagger$ \\ (From the Departments of Medicine and Surgery, University of Southern California School of \\ Medicine, and Los Angeles County General Hospital, Los Angeles, Calif.)
}

(Submitted for publication November 20, 1961; accepted February 1, 1962)

Since various types of surgical portal-systemic venous anastomoses are employed in the treatment of portal hypertension, it is of interest to know the effect of these operations on hepatic hemodynamics.

There is general agreement that the major hepatic hemodynamic disturbance in cirrhosis is an increase in vascular resistance in the liver, together with an increase in portal venous pressure, and a variable, moderate reduction in hepatic venous blood flow. The fact that wedged hepatic vein pressure is increased to near portal vein pressure level in most patients suggests that the major portion of the increased vascular resistance is on the hepatic venous side of the sinusoid. Portal hypertension, then, can be regarded as a compensatory mechanism for the increased vascular resistance caused by the cirrhotic liver. The possible contribution of increased splanchnic or hepatic arterial inflow to portal hypertension cannot be ignored, although if this were a major factor we would expect to find consistent increases in hepatic venous flow in cirrhosis. Creation of a surgical portal-systemic venous anastomosis would be expected to lower portal pressure and reduce portal inflow into the liver. The effect upon hepatic venous flow would be dependent upon the degree of reduction in portal venous inflow that existed prior to surgery, together with any adjustments that might take place in hepatic arterial flow.

Bradley, Smythe, Fitzpatrick and Blakemore, using the standard sulfobromophthalein (BSP) method to measure liver blood flow, found an average fall of 22 per cent in five patients after

* Supported by grants from the National Institutes of Health (H1718) and the Los Angeles County Heart Association (no. 256).

$\dagger$ University of Southern California Research Fellow in Medicine. spleno-renal anastomosis (1). Splanchnic oxygen consumption did not change.

After total exclusion of portal blood from the liver by end-to-side portacaval shunt, the same workers found reductions in hepatic blood flow of 21,39 , and 46 per cent in three patients (1). Redeker, Geller and Reynolds noted an average reduction of 45 per cent in ten subjects (2). In the latter studies, as would be expected, wedged hepatic venous pressure levels fell in proportion to the fall in hepatic venous flow and the calculated postsinusoidal hepatic resistance did not change significantly. Arterial-hepatic venous oxygen difference increased in proportion to the drop in blood flow and there appeared to be little, if any, effect on hepatic oxygen uptake from the operation. These results suggest that, in patients with portal hypertension, portal venous inflow still represents a significant fraction of the total liver blood flow. However, the failure of hepatic oxygen uptake to drop significantly and the lack of any demonstrable deterioration in liver function after end-to-side portacaval shunt indicates that the reduction in hepatic blood flow is well tolerated.

The end-to-side portacaval shunt has the theoretical disadvantage of permanent withdrawal of portal venous flow. Should liver disease improve and the vascular resistance in the liver decrease, there is no possibility of a resumption of portal flow. A side-to-side portacaval shunt leaves the portal vein connected to the liver, but has the potential disadvantage that some hepatic arterial blood might be diverted from its usual course to the hepatic vein to run backward through the portal vein and the side-to-side anastomosis. This would reduce hepatic venous flow even more than an end-to-side portacaval shunt and could impair the liver's oxygen supply. The satisfactory clinical results in the series reported by Longmire, 
Mulder, Mahoney and Mellinkoff (3) encouraged us to proceed with an analysis of hepatic hemodynamics before and after side-to-side portacaval shunt. Using hepatic vein catheterization, we have made pre- and post-shunt measurements of hepatic venous blood flow (HBF), wedged hepatic venous pressure (WHVP), postsinusoidal vascular resistance (HR), and splanchnic oxygen consumption (SOC) in nine patients with cirrhosis. An attempt was made to keep the diameter of the opening between portal vein and vena cava between 1.2 and $1.5 \mathrm{~cm}$ in the hope that this would minimize the backflow of hepatic arterial blood through the shunt.

\section{MATERIAL AND METHODS}

All of the nine patients described in this report had alcoholic cirrhosis. They had been under medical observation for varying periods of time, sufficient to establish the diagnosis of cirrhosis and to ensure, through withdrawal of alcohol, liver function adequate to withstand surgery. They had all had upper gastrointestinal bleeding, with no demonstrable source other than esophageal varices.

Preoperatively, hepatic vein catheterization was performed by the usual technique (4). In all instances, measurements were made in a rightsided hepatic vein. WHVP was measured initially in as many locations as possible, using a Statham strain gage and a photographic recorder. Pressure in the inferior vena cava was recorded either before entering the liver or after withdrawal of the catheter from it, and this served as a zero point of reference for all WHVP measurements. After pressure recordings, the catheter was withdrawn in the hepatic vein to a location 3 to $4 \mathrm{~cm}$ from the vena cava. From 40 to $70 \mathrm{mg}$ BSP was then given as a priming dose and a continuous infusion of approximately $2 \mathrm{mg}$ of BSP per minute administered through an arm vein with a constant speed pump. After 25 minutes of BSP infusion, three pairs of blood samples were drawn simultaneously from a femoral artery and from the hepatic vein catheter. These were used for the determination of hepatic blood flow as described by Bradley, Ingelfinger, Bradley and Curry (4), and for the measurement of splanchnic oxygen consumption. BSP concentration in the serum was determined colorimetrically after the method of Gaebler (5). The hepatic plasma flow was computed from the hepatic removal rate of BSP and the peripheral arterial-hepatic venous BSP concentration difference. $\mathrm{HBF}$ was calculated from this value and the arterial hematocrit. The rate of BSP infusion (in milligrams per minute) was corrected for the rate of change of BSP concentration ( $\Delta$ BSP) in the arterial plasma by the formula of Bradley and associates (4), and the resultant value was taken to be the hepatic removal rate of BSP ( $\left.R_{B S P}\right)$. The validity of the values for hepatic blood flow obtained in this study was determined by the relationship of the rate of change of the arterial BSP concentration to the hepatic removal rate of BSP. It is felt that the correction applied for the rate of change of the arterial plasma BSP levels is, at best, an approximation, since the plasma volume is estimated from a nomogram. Therefore, as this correction factor becomes large in proportion to the value for hepatic BSP removal, the calculation of $\mathrm{HBF}$ becomes progressively less reliable. In this study, all values for $R_{B S P}$ were greater than $1.6 \mathrm{mg}$ per minute and the largest $\Delta \mathrm{BSP}$ was 0.019 mg per minute.

The values for hepatic resistance (HR) were determined by dividing WHVP by $\mathrm{HBF}$ and multiplying the quotient by a factor of 100 to bring the values near unity. If WHVP equals hepatic sinusoidal pressure, then HR represents the postsinusoidal vascular resistance.

Blood oxygen content and capacity were measured directly by the method of Van Slyke and Neill in one of the three pairs of samples. Blood oxygen saturation was measured on all samples with an oximeter, and oxygen content was calculated from the saturation value and the oxygen capacity. The average of the four values for arterial-hepatic venous oxygen difference was multiplied by the mean value for $\mathrm{HBF}$ to obtain splanchnic oxygen consumption. After the measurement of hepatic blood flow, the catheter was again advanced into the wedged position in the liver and WHVP recorded a second time. After August, 1959, the location of the catheter in a wedged position was confirmed by a roentgenogram taken immediately after the injection of $3 \mathrm{ml}$ of 90 per cent Hypaque (sodium diatrizoate) through the catheter (6).

At surgery, portal pressures were measured directly with a saline manometer, using the portal vein itself as a baseline. In most patients, the portal vein was clamped, and the effect of this maneuver on pressures on both the intestinal and hepatic side of the clamp was noted.

Postoperative catheterization was performed when the patient's clinical state and laboratory tests returned to their preoperative levels, which usually required from 2 to 3 months. In one case (BM) postoperative catheterization was delayed for 10 months because of the persistence of moderate jaundice, and in another (EN) the patient's failure to return for clinic appointments led to delay in the postoperative measurement to 8 months.

\section{RESULTS}

The pre- and postoperative hepatic venous catheterization measurements are listed in Table I. Mean preoperative values for HBF, WHVP, HR, $\mathrm{SOC}$, and arterial-hepatic vein oxygen difference are similar to those previously reported in ten cirrhotic patients before end-to-side portacaval shunt (2).

In the current study, preoperative $\mathrm{HBF}$ ranged from 560 to $2,140 \mathrm{ml}$ per minute, with a mean of 


\section{HBF}

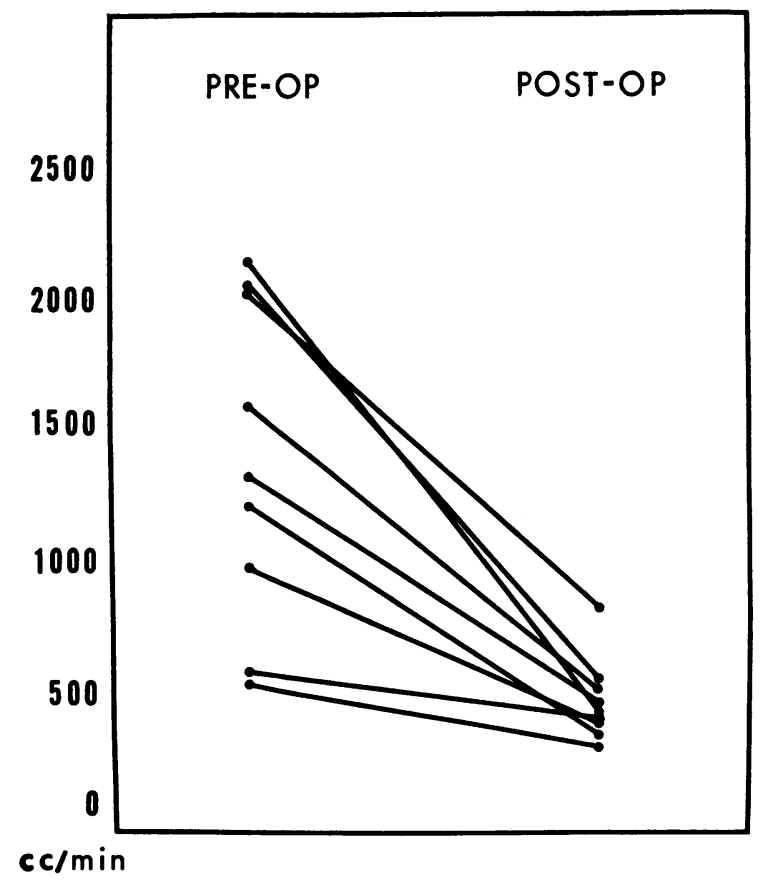

Fig. 1. EFfect of SIDE-TO-SIDE PORTACAval Shunt on HEPATIC BLOOD FLOW.

$1,380 \mathrm{ml}$ per minute. Postoperative $\mathrm{HBF}$ was lower in each patient, with a range of 335 to 890 and a mean of $497 \mathrm{ml}$ per minute. This is a statistically significant drop $(\mathrm{p}<0.001)$. When expressed as a percentage of the preoperative flow, HBF fell from 23 to 79 per cent, with a mean fall of 59 per cent (Figure 1).

Preoperatively, WHVP ranged from 14 to 25 $\mathrm{mm} \mathrm{Hg}$ above inferior vena caval pressure, with a mean of $19.0 \mathrm{~mm} \mathrm{Hg}$. There was a fall in WHVP in every instance postoperatively to levels of 6 to $11 \mathrm{~mm} \mathrm{Hg}$ (in one patient, IC, WHVP was not measured). Expressed as a per cent of the original value, the drop in WHVP averaged 55 per cent (Figure 2).

Postsinusoidal hepatic vascular resistance ranged from 0.76 to 3.00 (mean 1.72 ) arbitrary units preoperatively. The postoperative range was 0.79 to 2.50 , with a mean of 1.90 arbitrary units. Eight of the nine patients had both a preoperative and postoperative measurement, and the mean value did not change significantly (Figure 3).

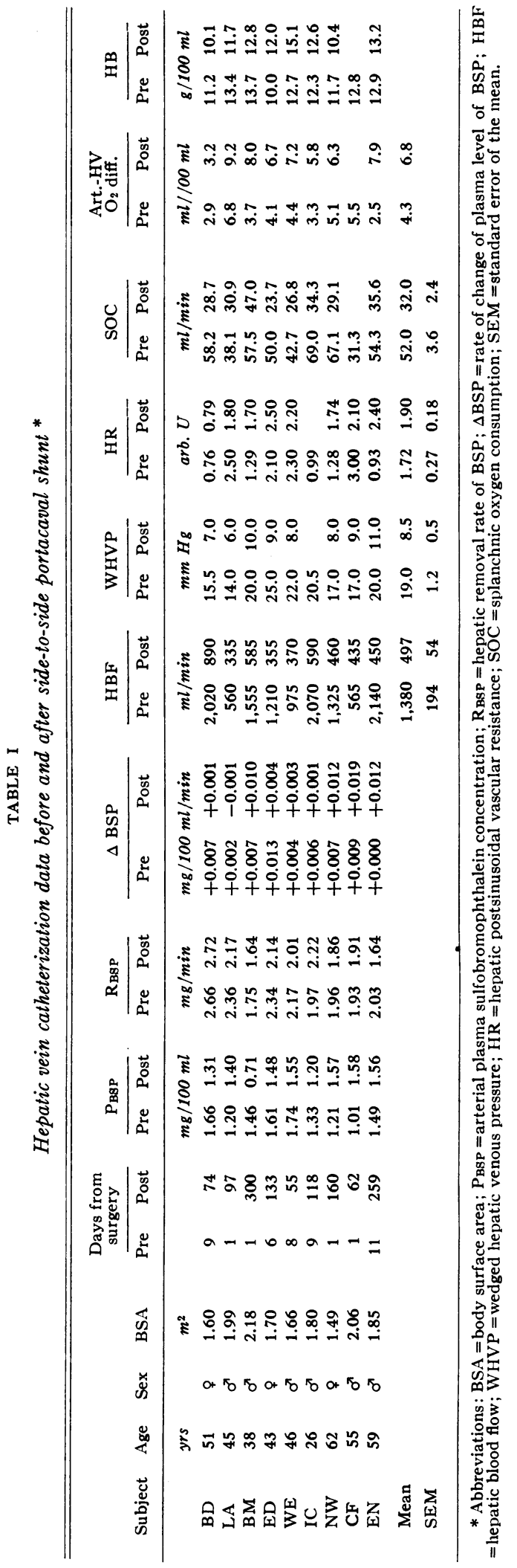


Splanchnic oxygen consumption ranged from 37 to $69 \mathrm{ml}$ per minute preoperatively, with a mean of $52 \mathrm{ml}$ per minute. Postoperatively, there was a fall in this measurement in the eight patients in whom it was made. Values ranged from 23 to 47 $\mathrm{ml}$ per minute, with a mean of $32 \mathrm{ml}$ per minute. When expressed as a percentage of the original value, postoperative fall averaged 37 per cent. The fall was highly significant statistically $(p<0.001)$ (Figure 4).

Direct portal pressure measured at surgery ranged from 31 to $48 \mathrm{~cm}$ saline (Table II). In every patient, except WE, an appreciable fall in portal pressure occurred with the creation of the surgical shunt. In all of the five patients in whom pressure studies were done after the application of a clamp to the portal vein, there was a rise in pressure on the intestinal side of the clamp and a drop in pressure on the hepatic side.

\section{DISCUSSION}

Warren and Muller found a rise in pressure on the hepatic side of a clamp placed across the portal vein in three of seven patients prior to porta-

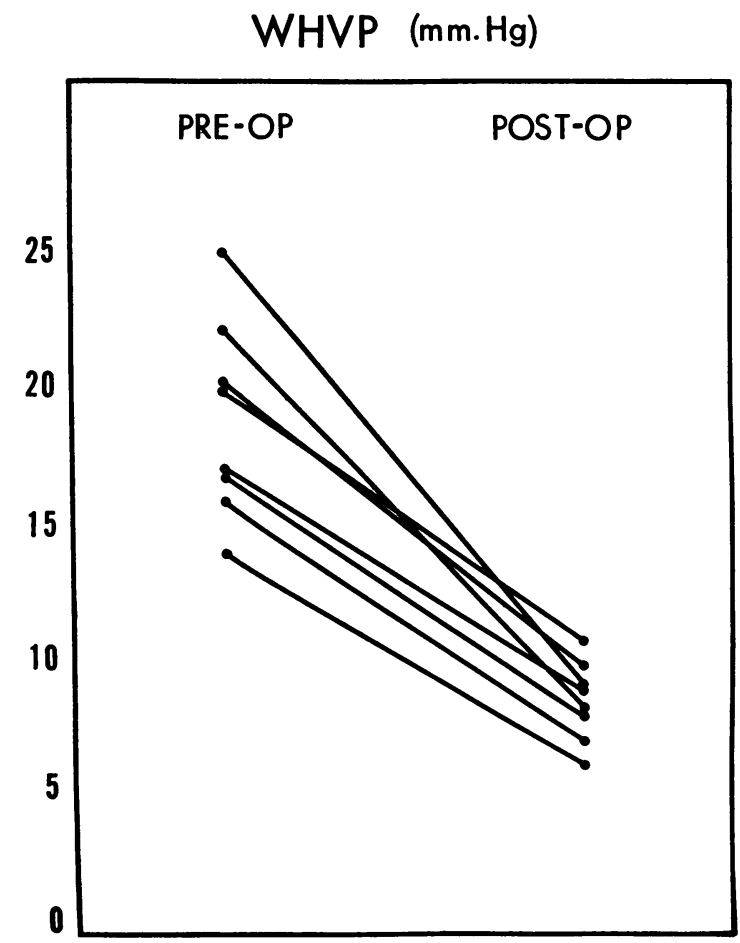

Fig. 2. EFFeCT OF SIDE-TO-SIDE PORTACAVAL SHUNT ON WEDGED HEPATIC VENOUS PRESSURE.
HEPATIC RESISTANCE

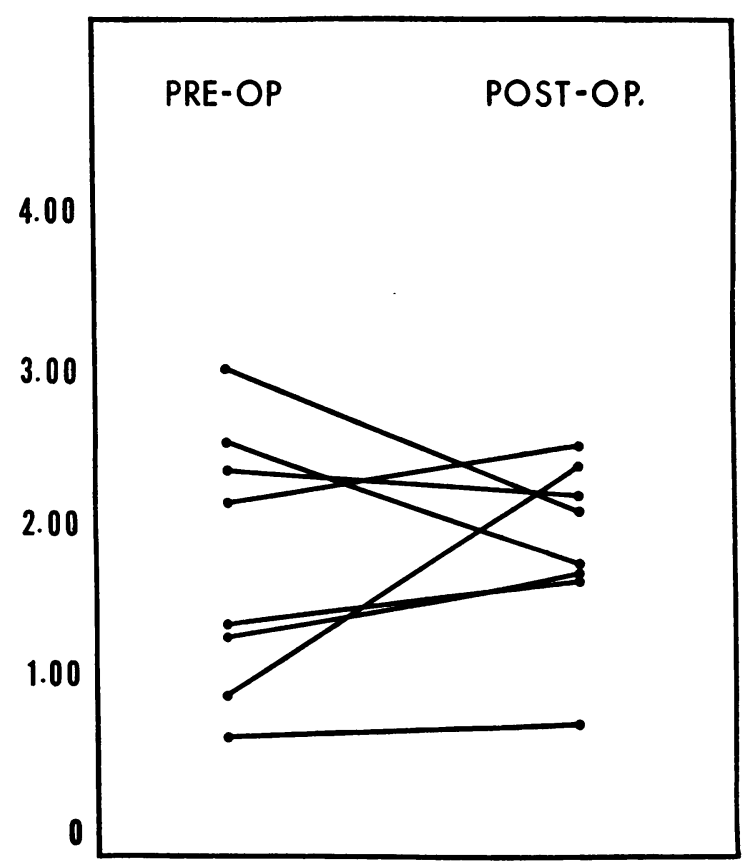

Fig. 3. EFFECT OF SIDE-TO-SIDE PORTACAVAL SHUNT ON CALCULATED HEPATIC POSTSINUSOIDAL VASCULAR RESISTANCE (ARBITRARY UNITS).

caval shunt (7), suggesting that the portal vein often may act as an outflow tract in cirrhosis. Such pressure changes have been an occasional but infrequent finding in our experience and were not seen in any of the five patients so tested in this study. Eighteen of the 19 patients included in this and in a previous report (2) showed a fall in

\section{TABLE II}

Direct pressure measurements (saline manometer) at surgery in patients undergoing side-to-side portacaval shunt

\begin{tabular}{|c|c|c|c|c|}
\hline \multirow[b]{3}{*}{ Patient } & \multicolumn{4}{|c|}{ Portal vein pressure } \\
\hline & \multirow[b]{2}{*}{$\begin{array}{l}\text { Before } \\
\text { shunt }\end{array}$} & \multicolumn{2}{|c|}{ After clamping } & \multirow[b]{2}{*}{$\begin{array}{l}\text { After } \\
\text { shunt }\end{array}$} \\
\hline & & $\begin{array}{l}\text { Hep. } \\
\text { limb }\end{array}$ & $\begin{array}{l}\text { Int. } \\
\text { limb }\end{array}$ & \\
\hline & \multicolumn{2}{|c|}{ cm saline } & \multicolumn{2}{|c|}{$\mathrm{cm}$ saline } \\
\hline $\begin{array}{l}\text { BD } \\
\text { LA } \\
\text { BM } \\
\text { ED } \\
\text { WE } \\
\text { IC } \\
\text { NW } \\
\text { CF } \\
\text { RN }\end{array}$ & $\begin{array}{l}32 \\
34 \\
35 \\
44 \\
38 \\
38 \\
48 \\
33 \\
31\end{array}$ & $\begin{array}{l}32 \\
30 \\
29 \\
26\end{array}$ & $\begin{array}{l}48 \\
56 \\
60 \\
41\end{array}$ & $\begin{array}{l}24 \\
20 \\
23 \\
20 \\
35 \\
27 \\
25 \\
15 \\
17\end{array}$ \\
\hline
\end{tabular}


HBF after portacaval shunt, indicating that portal vein flow is toward the liver in the great majority of patients with cirrhosis.

A marked fall in $\mathrm{HBF}$ was a consistent finding after side-to-side shunt. The fall averaged 59 per cent, and the mean postoperative HBF was only $497 \mathrm{ml}$ per minute. This drop in $\mathrm{HBF}$ is greater than that found previously after end-to-side shunt, where mean postoperative $\mathrm{HBF}$ was $801 \mathrm{ml}$ per minute and the average fall was 44 per cent (2). Direct statistical comparison of the values for HBF after side-to-side and end-to-side shunt was possible since preoperative $\mathrm{HBF}$ was similar in both groups of patients. Mean HBF after side-toside shunt was $304 \mathrm{ml}$ per minute lower than that after end-to-side shunt; the standard error of the difference between the means was 164 . Therefore, there is a 6 per cent possibility that the observed difference is due to chance alone. If there was, in fact, a greater fall in hepatic venous flow after sideto-side shunt in our patients, it can be readily explained by retrograde flow of hepatic arterial blood

\section{$\mathrm{O}_{2}$ UPTAKE (cc./min.)}

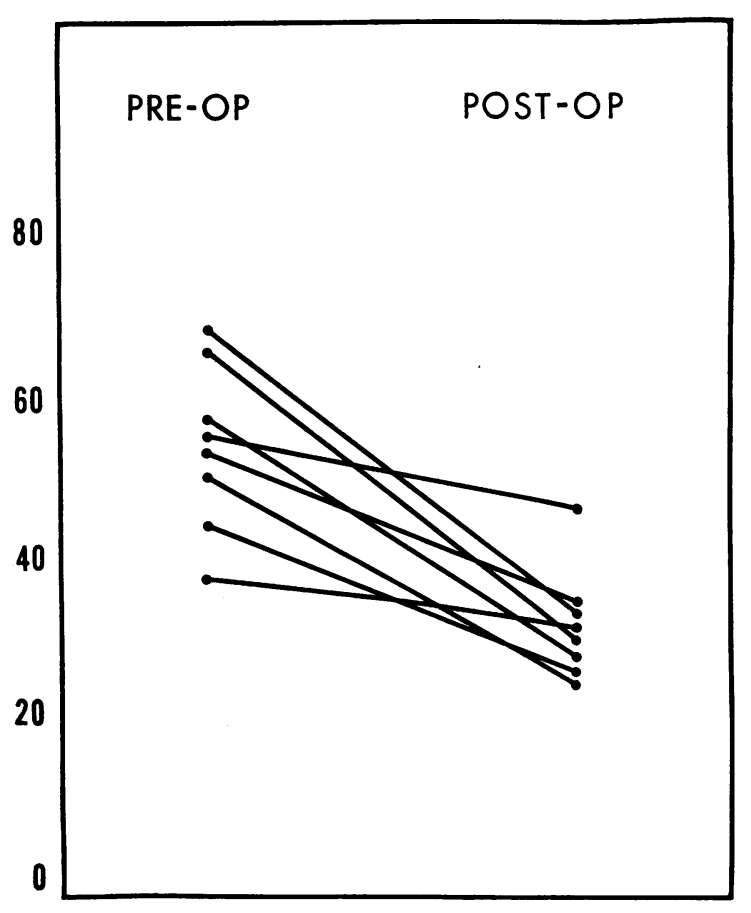

Fig. 4. EFfect of SIDE-To-SIDE PORTACAVAL Shunt on SPLANCHNIC OXYGEN CONSUMPTION. in the portal vein through the shunt orifice. This has been shown to occur in normal dogs after sideto-side shunt by Murray and Mulder $(8,9)$ and by Long and Lombardo (10). There are several lines of evidence indicating that it also occurs in man. At surgery, after construction of a side-toside shunt, Longmire and co-workers recovered isotopically labeled material in the hepatic limb of the portal vein after its injection into the hepatic artery (3). Warren and Muller found a rise in pressure in the portal vein near the liver after the portal vein was clamped on the hepatic side of the shunt (7). Contrast media injected through a catheter placed in the portal vein near the liver has been noted to flow toward the vena cava $(3,7)$. Side-to-side and "double-barreled" portacaval shunts are thought to be more effective than endto-side shunts in relieving ascites, due to the greater lowering of presinusoidal pressure that occurs when some blood leaves the liver via the portal vein $(11,12)$.

It is possible that anastomoses between the portal vein and vena cava larger than those (1.2 to $1.5 \mathrm{~cm}$ in diameter) used in our patients would result in more portal vein backflow and a greater fall in hepatic venous flow. We do not have data bearing on this question, since we have not measured pressure gradients directly across the shunts to note the size at which the orifice begins to offer significant resistance to shunted blood flow.

The applicability of the BSP method for the measurement of liver blood flow must be qualified under conditions where some blood leaves the liver via the portal vein. The accuracy of the calculation (Fick principle) of the volume of blood leaving the liver by the usual route (hepatic venous blood flow) will not be affected by blood leaving the liver through the portal vein, provided there is no BSP extracted from the latter. If there is some BSP extraction from this blood, then hepatic venous flow will be overestimated accordingly. The presence of retrograde portal flow cannot, then, account for an underestimation of hepatic venous flow by the standard BSP technique; it can result only in an overestimation that will be quantitatively dependent on the amount of BSP extracted from the portal effluent. On three occasions, we have obtained blood from the hepatic limb of the portal vein after the creation of 
a side-to-side anastomosis and have found BSP concentration to be only slightly $(0,11$, and 12 per cent) less than in arterial blood. This suggests that the postoperative values obtained for hepatic venous flow in this study are a little larger than the true values.

After a portacaval shunt, if there is no change in postsinusoidal vascular resistance, WHVP should fall in proportion to the fall in hepatic venous flow. Although there are some individual variations, the average fall in WHVP in the patients in this study was of approximately the same magnitude as the fall in $\mathrm{HBF}$, and the average value for $H R$ did not change significantly.

Postoperative splanchnic oxygen consumption was lower in the patients in this study than after end-to-side portacaval shunt. It is to be remembered that the preoperative figure includes the oxygen utilization for the entire splanchnic area, while the postoperative figure, if there is no portal inflow into the liver, represents only hepatic oxygen consumption. On the other hand, the postoperative figure probably overestimates hepatic oxygen consumption to a small extent, since hepatic blood flow is presumably overestimated. Also, it is possible that an appreciable amount of oxygen is extracted from any hepatic arterial blood that flows backward into the portal vein. Although the side-to-side shunt appears to cause a reduction in hepatic oxygen consumption, the many errors inherent in the calculations call for a cautious interpretation of the data.

Warren and Muller contend that the backflow of hepatic arterial blood into the portal vein after a side-to-side shunt is beneficial to the liver, since it increases the total perfusion of the organ (7). This would be true, of course, only if the blood flowing in the retrograde fashion has made some contact with liver parenchymal cells. They found oxygen saturation values of 70 to 86 per cent in blood from the hepatic limb of the portal vein, favoring their contention. We feel that further investigation is necessary to settle this important question about the functional value of retrograde portal flow, and such studies are now in progress in our own and, no doubt, in other laboratories. Blood from the hepatic limb of the portal vein and from the hepatic vein can be obtained simultaneously by catheter for comparison of BSP and oxygen content, and the direction of blood flow in the portal vein can be determined by the injection of contrast media. However, it is difficult to quantitate the flow of blood in the portal vein, and it will be necessary to know the amount of blood flowing in a retrograde fashion before any conclusions can be drawn about its contribution to liver function.

In spite of the marked reduction in hepatic venous blood flow and the fall in splanchnic oxygen consumption, the clinical results in our patients with side-to-side shunts have not been demonstrably different from the results after end-to-side shunt. One of the nine patients (WE) has been lost to follow-up. The other eight survived for an average of 21 months after surgery. Three $(\mathrm{BD}, \mathrm{NW}$, and $\mathrm{BM})$ are doing well with no serious complications from their cirrhosis. Three (LA, RN, and IC) have returned to intermittent use of alcohol, but are still doing well. One (ED) has developed deep jaundice and serious hepatic decompensation following prolonged heavy drinking. One patient (CF) has developed chronic intermittent encephalopathy. There has been only one episode of gastrointestinal bleeding (IC), presumably due to alcoholic gastritis, since both upper gastrointestinal X-ray and esophagoscopy were negative.

That marked falls in hepatic blood flow and, apparently, in hepatic oxygen consumption after sideto-side shunt are not accompanied by any obvious clinical deterioration is difficult to explain. One explanation would be that offered by Warren and Muller (7) ; i.e., that a significant volume of blood flowing retrograde in the portal vein contributes to the oxygen supply and function of the hepatic parenchymal cells. Another explanation has been proposed by Shaldon and co-workers; namely, that the reduction in hepatic venous flow after a portacaval shunt is largely due to elimination of nonfunctional blood flow through intrahepatic portal-hepatic venous shunts (13). However, this explanation does not account for the apparent reduction in hepatic oxygen consumption. A third possibility, which seems most likely to us, is that the cirrhotic liver is able to adapt fairly well to marked changes in blood flow, and that the dysfunction caused by portacaval shunting is not great enough to be easily recognizable. 


\section{SUMMARY}

Measurements of hepatic blood flow (HBF), wedged hepatic vein pressure (WHVP), postsinusoidal vascular resistance (HR), and splanchnic oxygen consumption (SOC) were made by hepatic vein catheterization in nine cirrhotic patients before and after side-to-side portacaval shunt. HBF dropped in each patient (average fall 59 per cent), as did WHVP (average fall 55 per cent). HR did not change significantly. SOC fell 37 per cent on the average, although arterialhepatic vein oxygen difference increased in all patients.

$\mathrm{HBF}$ fell to a degree greater than that previously noted after end-to-side portacaval shunt ( 59 as compared to 45 per cent). The statistical significance of this difference is questionable $(p<$ 0.06 ). If there actually is a greater fall in $\mathrm{HBF}$ after side-to-side shunt, it can be accounted for by retrograde flow of hepatic arterial blood through the proximal portal vein and the portal-vena caval anastomosis.

In spite of the marked fall in $\mathrm{HBF}$ and the apparent drop in SOC after side-to-side shunt, the clinical results were not demonstrably different from those after end-to-side shunt.

\section{REFERENCES}

1. Bradley, S. E., Smythe, C. M., Fitzpatrick, H. F., and Blakemore, A. H. The effect of a portacaval shunt on estimated hepatic blood flow and oxygen uptake in cirrhosis. J. clin. Invest. 1953, 32, 526.

2. Redeker, A. G., Geller, H. M., and Reynolds, T. B. Hepatic wedge pressure, blood flow, vascular resistance and oxygen consumption in cirrhosis be- fore and after end-to-side portacaval shunt. J. clin. Invest. 1958, 37, 606.

3. Longmire, W. P., Jr., Mulder, D. G., Mahoney, P. S. Mellinkoff, S. W. Side-to-side portacaval anastomosis for portal hypertension. Ann. Surg. 1958, 147, 881.

4. Bradley, S. E., Ingelfinger, F. J., Bradley, G. P., and Curry, J. J. The estimation of hepatic blood flow in man. J. clin. Invest. 1945, 24, 890.

5. Gaebler, O. H. Determination of bromsulphalein in normal, turbid, hemolyzed, or icteric serums. Amer. J. clin. Path. 1945, 15, 452.

6. Reynolds, T. B., Redeker, A. G., and Geller, H. M. Technique for verification of wedging of an hepatic venous catheter. Gastroenterology 1960, 38, 799.

7. Warren, W. D., and Muller, W. H., Jr. A clarification of some hemodynamic changes in cirrhosis and their surgical significance. Ann. Surg. 1959, $150,413$.

8. Murray, J. F., and Mulder, D. G. The effects of retrograde portal venous flow following side-toside portacaval anastomosis: A comparison with end-to-side shunts. J. clin. Invest. 1961, 40, 1413.

9. Mulder, D. G. The role of surgery in the treatment of portal hypertension. Amer. J. Gastroent. 1960, 33, 305.

10. Long, R. T. L., and Lombardo, C. R. Hemodynamic observations on the hepatic circulation: Modifications produced by portacaval shunting (abstract). J. clin. Invest. 1959, 38, 1021.

11. McDermott, W. V., Jr. The treatment of cirrhotic ascites by combined hepatic and portal decompression. New Engl. J. Med. 1958, 259, 897.

12. Welch, C. S., Welch, H. F., and Carter, J. H. The treatment of ascites by side to side portacaval shunt. Ann. Surg. 1959, 150, 428.

13. Shaldon, S., Chiandussi, L., Guevara, L., Caesar, J., and Sherlock, S. The estimation of hepatic blood flow and intrahepatic shunted blood flow by colloidal heat-denatured human serum albumin labeled with $\mathrm{I}^{131}$. J. clin. Invest. 1961, 40, 1346. 